\title{
The prevalence of edentulism and their related factors in Indonesia, 2014/15
}

Supa Pengpid ${ }^{1,2}$ and Karl Peltzer $2,3^{*}$ (D)

\begin{abstract}
Background: Little information exists about the loss of all one's teeth (edentulism) among older adults in Indonesia. The aim of this study was to investigate the prevalence of edentulism and associated factors among older adults in Indonesia.
\end{abstract}

Method: This study examines the self-reported prevalence of edentulism and associated factors among older adults (50 years and older) in a cross-sectional national study using the Indonesia Family Life Survey IFLS-5, 2014/15. The community-based study uses a multi-stage stratified sampling design to interview and assess household members, with a household response rate of over $90 \%$.

Results: The overall prevalence of edentulism was 7.2, 29.8\% in 80 years and older and $11.8 \%$ in those with no formal education. In adjusted Poisson regression analysis, older age, living in five major island groups and having functional disability were associated with edentulism. In addition, among men, having quit and current tobacco use and among women, having low social capital were associated with edentulism. Further, in adjusted analysis, among men, edentulism was positively associated with hypertension and negatively associated with diabetes, and among women, edentulism was associated with functional disability.

Conclusions: Results suggest that overall and/or among men or women that older age, living in five major island groups, having functional disability, tobacco quitters and users and those with low social capital was associated with edentulism. The identified associated factors of edentulism may be utilized in oral health programmes targeting older adults in Indonesia.

Keywords: Edentulism, Nutrition, Health status, Tobacco use, Older adults, Indonesia

\section{Background}

Edentulism (=having lost all of one's natural teeth) is a significant public health problem globally because of its high prevalence $(>10 \%$ in individuals 50 years and older) and related disability $[1,2]$. The disability-adjusted life-years (DALYs) of oral conditions dramatically increased between 1990 and 2015 (16.9 million years live with disability) [3]. Among oral disorders, edentulism accounted for more than one third (7.6 million DALYs) of the oral disorder disability burden, globally [4]. Monitoring the occurrence of edentulism [5] provides an indication of both population oral health and oral health care system response [6].

\footnotetext{
* Correspondence: kpeltzer@hsrc.ac.za

${ }^{2}$ Department of Research \& Innovation, University of Limpopo, Turfloop, South Africa

${ }^{3}$ HIV/AIDS/STIs and TB (HAST) Research Programme, Human Sciences Research Council, Private Bag X41, Pretoria 0001, South Africa

Full list of author information is available at the end of the article
}

There is a lack of community data on oral health among older adults in low- and middle-income countries [7]. Based on data from the World Health Survey, conducted from 2002 to 2004, the prevalence of self-reported edentulism among persons 50 years and older in countries of the Southeast Asian region were $4.2 \%$ in Laos, $22.2 \%$ in Malaysia, 2.4\% in Myanmar, 14.6\% in the Philippines and $5.6 \%$ in Vietnam [1]. In a more recent study (2007-2008) among adults 50 years and older, the overall prevalence of edentulism was $11.7 \%$ in the six middle-income countries, with India, Mexico, and Russia having higher prevalence rates (16.3-21.7\%) than China, Ghana, and South Africa $(3.0-9.0 \%)[2,8]$. In Indonesians aged 65 years or over the prevalence of measured edentulism was $17.6 \%$ in 2007 [9].

Using a social determinants of health approach, factors associated with edentulism may include, in addition to caries and periodontal disease [10], sociodemographic

(c) The Author(s). 2018 Open Access This article is distributed under the terms of the Creative Commons Attribution 4.0 International License (http://creativecommons.org/licenses/by/4.0/), which permits unrestricted use, distribution, and reproduction in any medium, provided you give appropriate credit to the original author(s) and the source, provide a link to the Creative Commons license, and indicate if changes were made. The Creative Commons Public Domain Dedication waiver (http://creativecommons.org/publicdomain/zero/1.0/) applies to the data made available in this article, unless otherwise stated. 
factors such as increasing age, female gender, no or lower education, lower economic status and rural residence $[2,8,11,12]$. Along with socioeconomic factors, health risk behaviours, such as smoking and former smoking remain strong predictors of edentulism [2, 11, 13-16]. Having chronic diseases [17], such as diabetes [18], having underweight [11], arthritis $[2,19]$, asthma $[2,11]$, depression [11, 17], reduced physical function [11], functional disability $[2,12]$, poor self-rated health $[12,17]$, lack of social support [17] and lack of social capital [20,21] have also been found to be associated with edentulism. On the other hand, edentulism has been associated with poor health status [12, 22], insufficient fruit and vegetable consumption [22, 23], smoking [24], underweight, poor nutrition [25-27], overweight/obesity [27-29], hypertension [30, 31], angina [32], strokes [33], diabetes [25, 34], rheumatoid arthritis [25], asthma [25], and functional disability $[35,36]$.

There is a lack of studies on edentulism and associated factors in Indonesia [37, 38]. The aim of this study was to investigate the prevalence of edentulism and associated factors among older adults in Indonesia. The objectives include: (1) to estimate the prevalence of self-reported edentulism in older adults, and (2) to identify possible factors such as sociodemographics and health variables associated with edentulism in Indonesia.

\section{Method}

\section{Study design and participants}

Secondary data from the fifth wave of the "Indonesia Family Life Survey (IFLS-5) 2014-15" were analysed, being the only of the five surveys that assessed edentulism [39]. The IFLS- 5 is a community survey interviewing household members (7994 50 years and older with complete endentulism measurements) selected by multistage stratified sampling representing $83 \%$ of the Indonesian population, with a household response rate of over $90 \%$, more details $[39,40]$.

\section{Measures}

Edentulism was assessed with the question, "Have you lost all your teeth?" (Yes, No) [39].

Socio-demographic variables included age, sex, education, area of residence, province, region and subjective socioeconomic background $[39,40]$.

Social capital was assessed with 4 items related to the past 12 month participation in "1) Community meeting, 2) Voluntary labour, 3), Programme to improve the village/ neighbourhood, and 4) Religious activities." Response options, were "yes" or "no" [39]. (Cronbach's alpha 0.59). Those who scored 0 times with "yes" were considered as having low social capital.
Self-reported health status was measured with the item, "In general, how is our health?" (Responses ranged from $1=$ Very healthy to $4=$ Unhealthy) [39].

Nutrition status. Heights and weights were taken using standard procedures [39], and body mass index (BMI) calculated according to Asian criteria: "underweight $\left(<18.5 \mathrm{~kg} / \mathrm{m}^{2}\right)$, normal weight (18.5 to $\left.<23.0 \mathrm{~kg} / \mathrm{m}^{2}\right)$, overweight (23.0 to $<25.0 \mathrm{~kg} / \mathrm{m}^{2}$ ) and $25+\mathrm{kg} / \mathrm{m}^{2}$ as obesity" [41].

Functional disability was assessed by 5 items of Activity of Daily Living (ADL) and 6 items of Instrumental Activity of Daily Living (IADL) [42, 43]. A total functional disability score was calculated, with having no difficulty $=0$ and one or more ADL/IADL items $=1$.

Tobacco use was grouped into never, quitters and current tobacco users, following the questions of ever and current use of various tobacco products $[39,40]$.

Inadequate fruit and vegetable consumption was defined as eating less than 3 days a week fruits and less than daily vegetables, following questions on the number of days in the past week vegetables (green leafy vegetables and carrots) and fruits (banana, papaya and mango) had been consumed $[39,40]$.

Chronic condition was measured based on health care provider diagnosed "Diabetes or high blood sugar, High blood pressure, Heart attack, coronary heart disease, angina or other heart problems, Stroke, Arthritis and Asthma" (Yes, No) [39, 40].

\section{Hypertension}

Average blood pressure was calculated arithmetically for three averaged measurements of systolic and diastolic blood pressure, assessed by using standard procedures [39]. Hypertension was defined as "SBP $\geq 140 \mathrm{~mm} \mathrm{Hg}$ and/or DBP $\geq 90 \mathrm{~mm} \mathrm{Hg}$ and/or current use of antihypertensive medication". [44].

The Centres for Epidemiologic Studies Depression Scale (CES-D: 10 items) was used to assess depressive symptoms, and scores of 10 or more were classified as having depressive symptoms [45] (Cronbach's alpha $=0.67)$.

\section{Data analysis}

Descriptive statistics were used to describe the variables. Nonparametric tests were used for trend analyses across ordered groups. Associations between key outcomes of edentulism and sociodemographic and health variables were evaluated by calculating prevalence ratios (PR). Poisson regression was used for evaluation of the association of explanatory variables for the outcome of edentulism (binary dependent variable). The Pearson goodness-of-fit test was used. Logistic regression was used to determine the association of edentulism on various health outcome variables. The Hosmer-Lemeshow goodness-of-fit test was used to evaluate multivariable model fit. Potential 
multi-collinearity between variables was assessed with variance inflation factors, none of which exceeded critical value. $P<0.05$ was considered significant. "Cross-section analysis weights were applied to correct both for sample attrition from 1993 to 2014, and then to correct for the fact that the IFLS-1 sample design included over-sampling in urban areas and off Java. The cross-section weights are matched to the 2014 Indonesian population, again in the 13 IFLS provinces, in order to make the attrition-adjusted IFLS sample representative of the 2014 Indonesian population in those provinces." [39] Both the 95\% confidence intervals and $P$-values were adjusted considering the survey design of the study. All analyses were done with STATA software version 13.0 (Stata Corporation, College Station, TX, USA).

\section{Results}

\section{Sample characteristics}

The total sample included 7994 older adults, 50 years and older (mean age 62.8 years, $\mathrm{SD}=9.8$, age range of 50-110 years) in Indonesia. The proportion of women was $51.9,72.2 \%$ had no or elementary education, $44.2 \%$ described themselves as having medium economic status, $52.0 \%$ resided in urban areas, 58.1\% were living in Java and $20.8 \%$ had low social capital. Regarding health status, $32.9 \%$ rated their health as unhealthy, and $31.3 \%$ had at least one functional disability. In all, $14.1 \%$ of participants were underweight and $21.3 \%$ overweight or obese, $33.5 \%$ infrequently consumed fruit and vegetables, $33.3 \%$ were current tobacco users and $9.8 \%$ quit tobacco use. In terms of chronic conditions, $6.3 \%$ had diabetes, 58.5\% hypertension, $3.6 \%$ heart attack, angina or other heart problems, $2.9 \%$ had a stroke, $11.8 \%$ had arthritis, $11.8 \%$ asthma and $17.0 \%$ depressive symptoms. The overall prevalence of edentulism was $7.2,7.6 \%$ among women and $6.8 \%$ among men, and among those 50 to 59 years $3.1 \%$ and those aged 80 years and older $29.8 \%$, and with no education the prevalence of edentulism was $11.8 \%$ and those with higher education $2.1 \%$ (see Table 1).

\section{Associations with edentulism}

In adjusted Poisson regression analysis, older age, living in five major island groups and having functional disability were associated with edentulism. In addition, among men, having quit and current tobacco use and among women, having low social capital were associated with edentulism. In further adjusted age stratified analysis, among 50 to 64 year olds, being male was negatively (Adjusted Prevalence Ratio: $\mathrm{APR}=0.60, \mathrm{CI}=0.37,0.98$ ) and having underweight as positively $(\mathrm{APR}=1.85, \mathrm{CI}=$ $1.20,2.83$ ) associated with edentulism (see Table 2).

\section{Associations between edentulism and health outcomes}

In order to estimate the independent association between edentulism and 13 individual health outcomes, 13 separate multivariable models are calculated with edentulism as predictor and each health outcome as dependent variable. In adjusted analysis, among men, edentulism was positively associated with hypertension and negatively associated with diabetes and among women, edentulism was associated with functional disability (see Table 3 ).

\section{Discussion}

The study found in a national community-based survey among individuals 50 years and older, a $7.2 \%$ self-reported prevalence of edentulism in 2014/15 in Indonesia, which is similar to a measured survey of $17.6 \%$ in 2007 in Indonesia in individuals 65 years and older [7] (in this study $15.7 \%$ in the 65 years and older age group) and to what was found previously in China and South Africa [2]. The found prevalence rate of edentulism in Indonesia was higher than previously found in Ghana, Laos, Myanmar and in Vietnam, and lower than in India, Malaysia, Mexico, Philippines and Russia and the global prevalence of $14.0 \%[1,2,15]$. The lower than global prevalence rate of edentulism in this study in Indonesia may be attributed to a lower consumption of non-refined carbohydrates and consequently lower dental caries and eventually tooth loss [1, 46]. The study found a significantly higher prevalence of edentulism in the five major island groups (Bali, West Nusa Tenggara, South Kalimantan, and South Sulawesi) than in Java and Sumatra. Reasons for this are not clear. It is possible that in the five major island groups greater gaps in dental care access exists than in Java and Sumatra.

The study found, in agreement with previous studies $[2,15,47-50]$, that increasing age and in bivariate analysis having no education were associated with edentulism. It is possible that having no education translates into lower oral health knowledge and lower oral health services utilization where available [46]. Some previous studies [2, 48, 49] found a preponderance of edentulism among women and those living in rural areas, while in this study overall no significant gender and urban-rural differences were found. However, in age stratified analysis, among 50 to 64 year-olds, women had a higher prevalence of edentulism than men. Lower economic status was in this study not associated with edentulism, as found in some previous other studies $[2,48,51]$. This may be because economic status was assessed with a subjective measure, rather than an objective measure. Low social capital was in this study among women associated with edentulism. This finding is consistent with previous studies $[20,52]$. It is possible that persons that belong to social networks are more likely to follow 
Table 1 Sample characteristics and prevalence rate of edentulism among older adults in Indonesia

\begin{tabular}{|c|c|c|c|}
\hline & \multirow{2}{*}{$\begin{array}{l}\text { Total sample } \\
N(\%)\end{array}$} & \multicolumn{2}{|c|}{ Prevalence rate of edentulism } \\
\hline & & $\bar{n}$ & $\%(95 \% \mathrm{Cl})^{\mathrm{a}}$ \\
\hline \multicolumn{4}{|l|}{ Sociodemographics } \\
\hline All & 7994 & 685 & $7.2(6.7,7.8)$ \\
\hline \multicolumn{4}{|l|}{ Age in years } \\
\hline $50-59$ & $4024(52.6)$ & 142 & $3.1(2.5,3.7)$ \\
\hline $60-69$ & $2226(27.9)$ & 169 & $6.4(5.4,7.5)$ \\
\hline $70-79$ & $1251(14.0)$ & 222 & $15.9(13.8,18.2)$ \\
\hline 80 or more & $493(5.5)$ & 152 & $29.8(25.5,34.4) P$ - trend $<0.001$ \\
\hline \multicolumn{4}{|l|}{ Sex } \\
\hline Female & $4317(51.9)$ & 392 & $7.6(6.8,8.5)$ \\
\hline Male & $3677(48.1)$ & 293 & $6.8(6.0,7.7)$ \\
\hline \multicolumn{4}{|l|}{ Education } \\
\hline None & $1324(16.7)$ & 185 & $11.8(10.0,13.8)$ \\
\hline Elementary & $4308(55.5)$ & 373 & $7.3(6.5,8.1)$ \\
\hline High school & $1723(21.1)$ & 92 & $4.7(3.8,5.8)$ \\
\hline Higher education & $569(6.8)$ & 16 & $2.1(1.2,3.7)$ \\
\hline \multicolumn{4}{|l|}{ Subjective economic background } \\
\hline Poor & $2072(31.0)$ & 135 & $6.5(5.5,7.7)$ \\
\hline Medium & $3024(42.3)$ & 194 & $6.3(5.2,7.5)$ \\
\hline Rich & $1789(26.7)$ & 112 & $6.8(6.0,7.8)$ \\
\hline Rural & $3541(48.0)$ & 334 & $7.9(7.0,8.9)$ \\
\hline Urban & $4453(52.0)$ & 351 & $6.6(5.8,7.4)$ \\
\hline \multicolumn{4}{|l|}{ Region } \\
\hline Sumatra & $1659(20.8)$ & 130 & $6.6(5.5,7.8)$ \\
\hline Java & $4647(58.1)$ & 309 & $6.4(5.7,7.2)$ \\
\hline Main island groups ${ }^{b}$ & $1688(21.1)$ & 246 & $14.8(13.1,16.7)$ \\
\hline Social capital (low) & $1467(20.8)$ & 134 & $9.1(7.8,10.7)$ \\
\hline \multicolumn{4}{|l|}{ Health variables } \\
\hline Self-rated health (Unhealthy) & $2849(32.9)$ & 335 & $9.9(8.8,11.2)$ \\
\hline \multicolumn{4}{|l|}{ Body mass index } \\
\hline Normal & $2856(39.0)$ & 258 & $7.4(6.4,8.4)$ \\
\hline Underweight & $1063(14.1)$ & 145 & $11.7(9.7,13.9)$ \\
\hline Overweight & $1177(15.8)$ & 85 & $5.6(4.4,7.0)$ \\
\hline Obese & $2355(31.1)$ & 98 & $3.8(3.0,4.7)$ \\
\hline Functional disability & $2639(31.3)$ & 490 & $12.6(11.3,14.0)$ \\
\hline \multicolumn{4}{|l|}{ Tobacco use } \\
\hline Never & $4663(56.9)$ & 371 & $6.6(5,9,7.4)$ \\
\hline Quit & $832(9.8)$ & 103 & $11.5(9.3,14.0)$ \\
\hline Current & $2499(33.3)$ & 211 & $7.1(6.1,8.2)$ \\
\hline Diabetes & $505(6.3)$ & 31 & $5.3(3.6,7.7)$ \\
\hline Arthritis & $1037(11.8)$ & 108 & $8.1(6.6,10.0)$ \\
\hline Asthma & $284(3.4)$ & 34 & $10.1(7.0,14.3)$ \\
\hline Depression symptoms & $1166(17.0)$ & 74 & $6.3(5.1,7.9)$ \\
\hline Fruit ( $<3$ days/week) and vegetable consumption ( $<$ daily/week) & $2119(33.5)$ & 141 & $6.7(5.7,7.8)$ \\
\hline
\end{tabular}


Table 1 Sample characteristics and prevalence rate of edentulism among older adults in Indonesia (Continued)

\begin{tabular}{llll}
\hline & Total sample & \multicolumn{2}{l}{ Prevalence rate of edentulism } \\
\cline { 3 - 4 } & $N(\%)$ & 417 & $9.5(8.7,10.4)$ \\
\hline Hypertension & $4391(58.5)$ & $417)^{\text {a }}$ & $9.1(6.1,13.4)$ \\
Heart attack, coronary heart disease, angina, or other heart problems & $299(3.6)$ & 29 & $13.2(9.0,18.9)$ \\
Stroke & $243(2.9)$ & 31 & \\
\hline
\end{tabular}

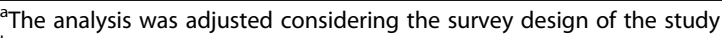

${ }^{b}$ Major Island groups: Bali, West Nusa Tenggara, South Kalimantan, and South Sulawesi

Table 2 Associations with edentulism estimated by Poisson regression

\begin{tabular}{|c|c|c|c|}
\hline & All & Men & Women \\
\hline Variable & Adjusted Prevalence Ratio ${ }^{a}(95 \%$ Cl) & Adjusted Prevalence Ratio ${ }^{a}(95 \%$ Cl) & Adjusted Prevalence Ratio ${ }^{a}(95 \% \mathrm{Cl}$ ) \\
\hline \multicolumn{4}{|l|}{ Sociodemographics } \\
\hline \multicolumn{4}{|l|}{ Age in years } \\
\hline $50-59$ & 1 (Reference) & 1 (Reference) & 1 (Reference) \\
\hline $60-69$ & $2.21(1.68,2.91)^{* * *}$ & $2.38(1.55,3.68)^{* * *}$ & $2.13(1.52,3.00)^{* * *}$ \\
\hline $70-79$ & $4.89(3.65,6.56)^{* * *}$ & $4.92(3.10,7.79)^{* * *}$ & $5.05(3.52,7.25)^{* * *}$ \\
\hline 80 or more & $5.94(3.76,9.39)^{* * *}$ & $7.91(4.27,14.64)^{* * *}$ & $4.33(2.08,9.01)^{* * *}$ \\
\hline \multicolumn{4}{|l|}{ Sex } \\
\hline Female & 1 (Reference) & - & - \\
\hline Male & $0.83(0.63,1.10)$ & & \\
\hline \multicolumn{4}{|l|}{ Education } \\
\hline None & 1 (Reference) & 1 (Reference) & 1 (Reference) \\
\hline Elementary & $1.20(0.88,1.64)$ & $1.00(0.58,1.72)$ & $1.28(0.86,1.78)$ \\
\hline High school/Higher education & $0.88(0.59,1.30)$ & $0.86(0.46,1.63)$ & $0.79(0.48,1.32)$ \\
\hline \multicolumn{4}{|l|}{ Subjective economic background } \\
\hline Poor & 1 (Reference) & 1 (Reference) & 1 (Reference) \\
\hline Medium & $1.12(0.88,1.43)$ & $1.12(0.79,1.59)$ & $1.15(0.83,1.59)$ \\
\hline Rich & $1.27(0.95,1.69)$ & $1.40(0.91,2.16)$ & $1.19(0.82,1.73)$ \\
\hline Urban residence (base = rural) & $1.10(0.88,1.38)$ & $0.98(0.70,1.35)$ & $1.28(0.94,1.73)$ \\
\hline \multicolumn{4}{|l|}{ Region } \\
\hline Sumatra & 1 (Reference) & 1 (Reference) & 1 (Reference) \\
\hline Java & $0.77(0.59,1.00)$ & $1.14(0.74,1.75)$ & $0.56(0.40,0.79)^{* * *}$ \\
\hline Main island groups & $2.08(1.59,2.71)^{* * *}$ & $2.75(1.79,4.21)^{* * *}$ & $1.74(1.24,2.45)^{* * *}$ \\
\hline Social capital (low) & $1.16(0.92,1.47)$ & $1.00(0.68,1.47)$ & $1.32(1.00,1.79)^{*}$ \\
\hline \multicolumn{4}{|l|}{ Health variables } \\
\hline Self-rated health (Unhealthy) & $1.07(0.86,1.36)$ & $1.17(0.83,1.65)$ & $0.97(0.73,1.29)$ \\
\hline Body mass index (Underweight) & $1.23(0.93,1.62)$ & $1.26(0.85,1.86)$ & $1.18(0.80,1.75)$ \\
\hline Functional disability & $1.34(1.08,1.66)^{* *}$ & $1.22(0.89,1.68)$ & $1.40(1.05,1.87)^{*}$ \\
\hline \multicolumn{4}{|l|}{ Tobacco use } \\
\hline Never & 1 (Reference) & 1 (Reference) & 1 (Reference) \\
\hline Quit & $1.25(0.86,1.82)$ & $1.95(1.12,3.39)^{*}$ & $0.73(0.27,1.92)$ \\
\hline Current & $1.17(0.87,1.56)$ & $1.64(1.01,2.69)^{*}$ & $0.89(0.51,1.55)$ \\
\hline Diabetes & $0.56(0.31,1.01)$ & $0.30(0.09,1.02)$ & $0.78(0.40,1.52)$ \\
\hline Arthritis & $0.93(0.69,1.24)$ & $0.80(0.47,1.38)$ & $0.97(0.69,1.38)$ \\
\hline Asthma & $0.89(0.52,1.51)$ & $0.45(0.16,1.29)$ & $1.26(0.69,2.31)$ \\
\hline Depression symptoms & $0.73(0.45,1.16)$ & $0.69(0.34,1.39)$ & $0.74(0.40,1.39)$ \\
\hline
\end{tabular}


Table 3 Associations between edentulism and health variables (outcomes) estimated by logistic regression

\begin{tabular}{|c|c|c|c|c|}
\hline \multirow[t]{2}{*}{ Health outcome } & \multicolumn{2}{|l|}{ Men } & \multicolumn{2}{|l|}{ Women } \\
\hline & $\overline{C O R}$ & $\mathrm{AOR}^{\mathrm{a}, \mathrm{b}}$ & $\overline{C O R}$ & $\mathrm{AOR}^{\mathrm{a}, \mathrm{b}}$ \\
\hline Health status (unhealthy) & $2.30(1.78,2.97)^{* * *}$ & $1.18(0.80,1.75)$ & $1.98(1.58,2.48)^{* * *}$ & $1.11(0.80,1.51)$ \\
\hline Functional disability & $2.40(1.83,3.84)^{* * *}$ & $1.36(0.96,1.92)$ & $3.30(2.59,4.20)^{* * *}$ & $1.43(1.05,1.95)^{*}$ \\
\hline Underweight (vs. normal weight) & $2.11(1.51,2.95)^{* * *}$ & $1.33(0.83,2.15)$ & $1.92(1.37,2.69)^{* * *}$ & $1.16(0.72,1.88)$ \\
\hline Overweigh or obesity (vs. normal weight) & $0.48(0.35,0.67)^{* * *}$ & $0.64(0.40,1.01)$ & $0.50(0.38,0.66)^{* * *}$ & $0.83(0.58,1.17)$ \\
\hline Infrequent fruit and vegetable consumption & $1.02(0.74,1.39)$ & $1.02(0.71,1.47)$ & $0.86(0.64,1.16)$ & $0.96(0.68,1.34)$ \\
\hline Current tobacco use & $0.89(0.69,1.16)$ & $1.15(0.76,1.75)$ & $2.16(1.44,3.24)^{* * *}$ & $1.01(0.55,1.85)$ \\
\hline Hypertension & $2.40(1.81,3.17)^{* * *}$ & $1.74(1.17,2.57)^{* *}$ & $2.00(1.54,2.58)^{* * *}$ & $0.93(0.62,1.39)$ \\
\hline Heart problems ${ }^{c}$ & $2.04(1.07,3.88)^{*}$ & $1.09(0.69,5.17)$ & $1.16(0.65,2.07)$ & $1.05(0.48,2.31)$ \\
\hline Stroke & $2.72(1.43,5.15)^{* *}$ & $0.89(0.25,3.18)$ & $2.90(1.02,5.19)^{* * *}$ & $1.35(0.31,5.87)$ \\
\hline Asthma & $2.16(1.25,3.72)^{* *}$ & $0.58(0.21,1.58)$ & $1.40(0.81,2.44)$ & $1.35(0.68,2.70)$ \\
\hline Arthritis & $1.29(0.84,1.97)$ & $0.88(0.50,1.56)$ & $1.58(1.18,2.10)^{* *}$ & $0.98(0.66,1.44)$ \\
\hline Diabetes & $0.61(0.29,1.32)$ & $0.29(0.09,0.98)^{*}$ & $1.26(0.78,2.03)$ & $0.92(0.47,0.82)$ \\
\hline Depression & $0.56(0.26,1.18)$ & $0.68(0.31,1.46)$ & $0.70(0.39,1.25)$ & $0.67(0.34,1.37)$ \\
\hline
\end{tabular}

COR crude odds ratio, $A O R$ adjusted odds ratio

${ }^{a}$ Adjusted for age, education, socioeconomic status, rural-urban, region, social capital and all other health variables, as shown in this table

${ }^{b}$ Hosmer-Lemeshow goodness-of-fit test between predicted and observed probabilities was for all models $P>0.05$

${ }^{\mathrm{C}} \mathrm{Heart}$ attack, coronary heart disease, angina, or other heart problems

${ }^{* * *} P<0.001$; ${ }^{*} P<0.01 ;{ }^{*} P<0.05$

health-enhancing behaviours and, hence, have better health and oral health [53-55]. Previous research also showed that the effect of edentulism on facial appearance, eating and speech may decline in social capital due to embarrassment $[1,56]$.

Previous studies $[2,18,48,57]$ found an association between former and current tobacco use and edentulism, which was confirmed in this study among men. Edentulism was also associated with former smokers in China [15]; China and Indonesia have the highest prevalence of tobacco use among men in the world. Smoking is a known risk factor for periodontitis and tooth loss, meaning that the higher prevalence of edentulism among tobacco users may be directly related to the negative effects of tobacco use on periodontal health $[18,57]$. Functional disability was found in this study to be both, a risk factor and a consequence of edentulism, which has also been found in previous studies $[2,12,35,36]$. It is possible that people with a functional disability are less likely visit dental health care services [12]. Unlike in some previous studies [12, 17, 22], this study did not find an association between poor self-rated health as a risk factor for and consequence of edentulism. Arthritis, asthma, diabetes, angina and depression were in this study not associated with edentulism, as this was found in some previous studies $[2,11,18,19]$.

Among having different chronic conditions, this study found that edentulism was associated with hypertension. Similar results were found in previous studies [30, 31]. It is possible that total tooth loss is a risk factor for developing hypertension, which may be attributed to dietary changes of not be able to consume nutritious foods [30].
Some studies [11, 25-27, 58] found a significant association between undernutrition as a risk factor and consequence of edentulism, both of which were confirmed in this study in bivariate analysis, and in age stratified adjusted analysis, among 50 to 64 year-olds, having underweight was associated with edentulism. In a study among older adults in care homes in Indonesia it was found that individuals who were underweight had a significantly lower number of functional tooth units than those with normal weight [38]. The loss of teeth changes digestive processes and food choices contributing to nutritional deficiencies $[38,58]$. Contrary to some previous studies [26-29, 59], this study found that edentulism was negatively associated with overweight or obesity in bivariate analysis. It is possible that edentulism caused individuals in this study to alter their diet, resorting to a diet that is high in fiber and low in saturated fat, reducing the risk of being obese. Contrary to some studies $[23,24]$, this study did not find that edentulism had a negative impact on fruit and vegetable consumption.

Contrary to some previous studies [24, 32-34], this study did not find an association between having edentulism and heart problems, stroke, asthma, arthritis, diabetes and depression. In a study in Indonesia the prevalence and severity of periodontitis (and consequently tooth loss) was not associated with arthritis [60] and among elderly in Indonesia, tooth loss was not associated with diabetes and heart diseases [10]. The diet and dietary habits of edentulous individuals in Indonesia may not be putting them at increased risk of heart diseases and diabetes [2]. It is also possible, since in this 
study arthritis, asthma, diabetes, and heart diseases were assessed by self-reported diagnosed conditions; they were underreported and thus contributing to these findings [2]. Sudiono [10] proposes that among elderly in Indonesia the loss of teeth may have been influenced by "a low demand for dental hygiene" and that "improvement of dental awareness and education in oral hygiene measures in such populations might reduce both diseases (dental caries and periodontitis) responsible for tooth loss and could improve quality of life in Indonesia."

\section{Study limitations}

Edentulism was only measured with one question. Oral examinations should be conducted in future investigations. The data analysed were based on a cross-sectional survey, so no causative conclusions be drawn between independent study variables and the prevalence of edentulism. Finally, the analysis was limited to the variables included in IFLS-5, and other factors such as inadequate oral hygiene and dental attendance found significant in previous investigations should be included in future research.

\section{Conclusions}

Almost one in ten older adults (50 years and above) Indonesians were edentate. Results suggest that overall and/or among men or women that older age, living in five major island groups, having functional disability, tobacco quitters and users and those with low social capital was associated with edentulism. The identified associated factors of edentulism may be utilized in oral health programmes targeting older adults in Indonesia.

\section{Abbreviations}

BMI: Body Mass Index; CES-D: Centres for Epidemiologic Studies Depression Scale; DBP: Diastolic Blood Pressure; EA: Enumeration Area; IFLS: Indonesian Family Life Survey; SBP: Systolic Blood pressure

\section{Acknowledgments}

The research was conducted based on the IFLS-5 conducted by RAND (http://www.rand.org/labor/FLS/IFLS.html). We thank RAND for providing the access to the survey data and the study participants who provided the survey data.

\section{Funding}

The authors received no specific funding for this work.

\section{Availability of data and materials}

The data for the current study from the Indonesian Family Life Survey (IFLS) are in the public domain and are accessible via the Rand Labor and Population website (https://www.rand.org/labor/FLS/IFLS.html).

\section{Authors' contributions}

KP and SP conceived and designed the analysis. KP drafted the manuscript and SP made critical revision of the manuscript for key intellectual content. Both authors read and approved the final version of the manuscript.

\section{Ethics approval and consent to participate}

The IFLS has been approved by ethics review boards of RAND and University of Gadjah Mada in Indonesia [13]. Written informed consent was obtained from all respondents prior to data collection.
Consent for publication

Not applicable

\section{Competing interests}

The authors declare that they have no competing interests.

\section{Publisher's Note}

Springer Nature remains neutral with regard to jurisdictional claims in published maps and institutional affiliations.

\section{Author details}

${ }^{1}$ ASEAN Institute for Health Development, Mahidol University, Salaya, Thailand. ${ }^{2}$ Department of Research \& Innovation, University of Limpopo, Turfloop, South Africa. ${ }^{3} \mathrm{HIV} / \mathrm{AIDS} / \mathrm{ST}$ Is and TB (HAST) Research Programme, Human Sciences Research Council, Private Bag X41, Pretoria 0001, South Africa.

Received: 26 October 2017 Accepted: 25 June 2018

Published online: 03 July 2018

\section{References}

1. Tyrovolas S, Koyanagi A, Panagiotakos DB, Haro JM, Kassebaum NJ, Chrepa V, Kotsakis GA. Population prevalence of edentulism and its association with depression and self-rated health. Sci Rep. 2016;6:37083. https://doi.org/10. 1038/srep37083.

2. Peltzer K, Hewlett S, Yawson AE, Moynihan P, Preet R, Wu F, Guo G, Arokiasamy P, Snodgrass JJ, Chatterji S, Engelstad ME, Kowal P. Prevalence of loss of all teeth (edentulism) and associated factors in older adults in China, Ghana, India, Mexico, Russia and South Africa. Int J Environ Res Public Health. 2014;11(11):11308-24. https://doi.org/10.3390/ijerph111111308.

3. Kassebaum NJ, Smith AGC, Bernabé E, Fleming TD, Reynolds AE, Vos T, Murray CJL, Marcenes W, GBD 2015 Oral Health Collaborators. Global, regional, and national prevalence, incidence, and disability-adjusted life years for oral conditions for 195 countries, 1990-2015: a systematic analysis for the global burden of diseases, injuries, and risk factors. J Dent Res. 2017; 96(4):380-7. https://doi.org/10.1177/0022034517693566.

4. GBD 2015 DALYs and HALE Collaborators. Global, regional, and national disability-adjusted life-years (DALYs) for 315 diseases and injuriesand healthy life expectancy (HALE), 1990-2015: a systematic analysis for the global burden of disease study 2015. Lancet. 2016;388(10053):1603-58. https://doi. org/10.1016/S0140-6736(16)31460-X.

5. Sussex PV. Edentulism from a New Zealand perspective -a review of the literature. NZ Dental J. 2008;104:84-96.

6. Thomson WM. Monitoring edentulism in older New Zealand adults over two decades: a review and commentary. Int J Dent. 2012;2012 https://doi. org/10.1155/2012/375407.

7. Kossioni AE. Current status and trends in oral health in community dwelling older adults: a global perspective. Oral Health Prev Dent. 2013;11:331-40.

8. Hewlett SA, Yawson AE, Calys-Tagoe BN, Naidoo N, Martey P, Chatterji S, Kowal P, Mensah G, Minicuci N, Biritwum RB. Edentulism and quality of life among older Ghanaian adults. BMC Oral Health. 2015;15:48. https://doi.org/ 10.1186/s12903-015-0034-6.

9. Ministry of Health Republic of Indonesia. Report on Result of National Basic Health Research (RISKESDAS). Indonesia: the National Institute of Health Research and Development, 2007.

10. Sudiono J. The features of degenerative diseases and their association with the loss of teeth in the elderly of East Jakarta (Indonesia). Southeast Asian J Trop Med Public Health. 2008;39(1):184-9.

11. Ren C, McGrath C, Yang Y. Edentulism and associated factors among community-dwelling middle-aged and elderly adults in China. Gerodontology. 2017;34(2):195-207. https://doi.org/10.1111/ger.12249.

12. Olofsson H, Ulander EL, Gustafson Y, Hörnsten C. Association between socioeconomic and health factors and edentulism in people aged 65 and older - a population-based survey. Scand J Public Health. 2017; https://doi. org/10.1177/1403494817717406.

13. Starr JM, Hall RJ, Macintyre S, Deary IJ, Whalley LJ. Predictors and correlates of edentulism in the healthy old people in Edinburgh (HOPE) study. Gerodontology. 2008;25(4):199-204. https://doi.org/10.1111/j.1741-2358. 2008.00227.x. 
14. Arora M, Schwarz E, Sivaneswaran S, Banks E. Cigarette smoking and tooth loss in a cohort of older Australians: the 45 and up study. J Am Dent Assoc. 2010;141:1242-9

15. Kailembo A, Preet R, Stewart Williams J. Common risk factors and edentulism in adults, aged 50 years and over, in China, Ghana, India and South Africa: results from the WHO Study on global AGEing and adult health (SAGE). BMC Oral Health. 2016;17(1):29. https://doi.org/10.1186/ s12903-016-0256-2.

16. Musacchio E, Perissinotto E, Binotto P, Sartori L, Silva-Netto F, Zambon S, Manzato E, Corti MC, Baggio G, Crepaldi G. Tooth loss in the elderly and its association with nutritional status, socio-economic and lifestyle factors. Acta Odontol Scand. 2007;65(2):78-86.

17. Saman DM, Lemieux A, Arevalo O, Lutfiyya MN. A population-based study of edentulism in the US: does depression and rural residency matter after controlling for potential confounders? BMC Public Health. 2014;14:65. https://doi.org/10.1186/1471-2458-14-65.

18. Islas-Granillo H, Borges-Yañez SA, Lucas-Rincón SE, Medina-Solís CE, Casanova-Rosado AJ, Márquez-Corona ML, Maupomé G. Edentulism risk indicators among Mexican elders 60-year-old and older. Arch Gerontol Geriatr. 2011;53:258-62

19. de Pablo P, Dietrich T, McAlindon TE. Association of periodontal disease and tooth loss with rheumatoid arthritis in the US population. J Rheumatol. 2008;35(1):70-6.

20. Kim EK, Jung YS, Kim KH, Kim KR, Kwon GH, Choi YH, Lee HK. Social capital and oral health: the association of social capital with edentulism and chewingability in the rural elderly. Arch Gerontol Geriatr. 2018;74:100-5. https://doi.org/10.1016/j.archger.2017.10.002

21. Tsakos G, Sabbah W, Chandola T, Newton T, Kawachi I, Aida J, Sheiham A Marmot MG, Watt RG. Social relationships and oral health among adults aged 60 years or older. Psychosom Med. 2013;75:178-86.

22. Medina-Solís CE, Pontigo-Loyola AP, Pérez-Campos E, Hernández-Cruz P, Avila-Burgos L, Mendoza-Rodríguez M, Maupomé G. Edentulism and other variables associated with self-reported health status in Mexican adults. Med Sci Monit. 2014:20:843-52. https://doi.org/10.12659/MSM.890100.

23. De Marchi RJ, Hugo FN, Padilha DM, Hilgert JB, Machado DB, Durgante PC, Antunes MT. Edentulism, use of dentures and consumption of fruit and vegetables in south Brazilian community-dwelling elderly. J Oral Rehabil. 2011;38(7):533-40. https://doi.org/10.1111/j.1365-2842.2010.02189.x.

24. Tsakos G, Herrick K, Sheiham A, Watt RG. Edentulism and fruit and vegetable intake in low-income adults. J Dent Res. 2010;89(5):462-7. https://doi.org/10. 1177/0022034510363247.

25. Felton DA. Complete edentulism and comorbid diseases: an update. J Prosthodont. 2016;25(1):5-20. https://doi.org/10.1111/jopr.12350.

26. Toniazzo MP, Amorim PS, Muniz FW, Weidlich P. Relationship of nutritional status and oral health in elderly: Systematic review with meta-analysis. Clin Nutr. 2017; https://doi.org/10.1016/j.clnu.2017.03.014

27. Tôrres LH, da Silva DD, Neri AL, Hilgert JB, Hugo FN, Sousa ML. Association between underweight and overweight/obesity with oral health among independently living Brazilian elderly. Nutrition. 2013;29(1):152-7. https://doi. org/10.1016/j.nut.2012.05.011.

28. Österberg T, Dey DK, Sundh V, Carlsson GE, Jansson JO, Mellström D. Edentulism associated with obesity: a study of four national surveys of 16,416 swedes aged 55-84 years. Acta Odontol Scand. 2010;68:360-7.

29. Nascimento GG, Leite FR, Conceição DA, Ferrúa CP, Singh A, Demarco FF. Is there a relationship between obesity and tooth loss and edentulism? A systematic review and meta-analysis. Obes Rev. 2016; 17(7):587-98. https://doi.org/10.1111/obr.12418.

30. Ayo-Yusuf OA, Ayo-Yusuf IJ. Association of tooth loss with hypertension. S Afr Med J. 2008;98:381-5.

31. Peres MA, Tsakos G, Barbato PR, Silva DA, Peres KG. Tooth loss is associated with increased blood pressure in adults-a multidisciplinary populationbased study. J Clin Periodontol. 2012;39(9):824-33. https://doi.org/10.1111/j. 1600-051X.2012.01916.X.

32. Medina-Solís CE, Pontigo-Loyola AP, Pérez-Campos E, Hernández-Cruz P, ÁvilaBurgos L, Kowolik MJ, Maupomé G. Association between edentulism and angina pectoris in Mexican adults 35 years of age and older: a multivariate analysis of a population-based survey. J Periodontol. 2014;85:406-16.

33. Del Brutto OH, Mera RM, Zambrano M, Del Brutto VJ. Severe edentulism is a major risk factor influencing stroke incidence in rural Ecuador (The Atahualpa Project). Int J Stroke. 2017;12(2):201-4. https://doi.org/10.1177/ 1747493016676621
34. Emami E, de Souza RF, Kabawat M, Feine JS. The impact of edentulism on oral and general health. Int J Dent. 2013;2013:498305. https://doi.org/10. 1155/2013/498305.

35. Starr JM, Hall R. Predictors and correlates of edentulism in healthy older people. Curr Opin Clin Nutr Metab Care. 2010;13(1):19-23. https://doi.org/10. 1097/MCO.0b013e328333aa37.

36. Yu YH, Lai YL, Cheung WS, Kuo HK. Oral health status and self-reported functional dependence in community-dwelling older adults. J Am Geriatr Soc. 2011;59(3):519-23. https://doi.org/10.1111/j.1532-5415.2010.03311.x.

37. Asia A, Kusdhany L, Rahardjo A, Bachtiar A. Association between tooth loss and the development of dementia on the Indonesian elders. JSM Dent. 2015;3(1):1050

38. Adiatman M, Ueno M, Ohnuki M, Hakuta C, Shinada K, Kawaguchi Y. Functional tooth units and nutritional status of older people in care homes in Indonesia. Gerodontology. 2013;30(4):262-9. https://doi.org/10.1111/j. 1741-2358.2012.00673.x.

39. Strauss J, Witoelar F, Sikoki B. The Fifth Wave of the Indonesia Family Life Survey (IFLS5): Overview and Field Report. 2016. WR-1143/1-NIA/NICHD, 2016.

40. Peltzer K, Pengpid S. High prevalence of depressive symptoms in a national sample of adults in Indonesia: childhood adversity, sociodemographic factors and health risk behaviour. Asian J Psychiatr. 2018;33:52-9. https://doi. org/10.1016/j.ajp.2018.03.017

41. Wen CP, David Cheng TY, Tsai SP, Chan HT, Hsu HL, Hsu CC, Eriksen MP. Are Asians at greater mortality risks for being overweight than Caucasians? Redefining obesity for Asians. Public Health Nutr. 2009;12:497-506.

42. Katz S, Ford AB, Moskowitz RW, Jackson BA, Jaffe MW. Studies of illness in the aged. JAMA. 1963;185(12):914-9.

43. Lawton MP, Brody EM. Assessment of older people: self-maintaining and instrumental activities of daily living. The Gerontologist. 1969;9(3-Part-1):179-86.

44. Chobanian AV, Bakris GL, Black HR, Cushman WC, Green LA, Izzo JL, et al. Seventh report of the Joint National Committee of Prevention, Detection, Evaluation, and Treatment of High Blood Pressure. Hypertension. 2003:42: 1206-52.

45. Andresen EM, Malmgren JA, Carter WB, Patrick DL. Screening for depression in well older adults: evaluation of a short form of the CES-D (Center for Epidemiologic Studies Depression Scale). Am J Prev Med. 1994;10(2):77-84.

46. van der Velden U, Amaliya A, Loos BG, Timmerman MF, van der Weijden FA, Winkel EG, Abbas F. Java project on periodontal diseases: causes of tooth loss in a cohort of untreated individuals. J Clin Periodontol. 2015;42(9):82431. https://doi.org/10.1111/jcpe.12446.

47. Doğan BG, Gökalp S. Tooth loss and edentulism in the Turkish elderly. Arch Gerontol Geriatr. 2012;54:e162-e166.

48. Gaio EJ, Haas AN, Carrard VC, Oppermann RV, Albandar J, Susin C. Oral health status in elders from South Brazil: a population-based study. Gerodontology. 2012;29:214-23.

49. Hugo FN, Hilgert JB, de Sousa Mda L, da Silva DD, Pucca GA Jr. Correlates of partial tooth loss and edentulism in the Brazilian elderly. Community Dent Oral Epidemiol. 2007;35:224-32

50. Mendes DC, Poswar Fde O, de Oliveira MV, Haikal DS, da Silveira MF, Martins AM, De Paula AM. Analysis of socio-demographic and systemic health factors and the normative conditions of oral health care in a population of the Brazilian elderly. Gerodontology. 2012;29:e206-14.

51. Moreira Rda S, Nico LS, Tomita NE. Spatial risk and factors associated with edentulism among elderly persons in Southeast Brazil. Cad Saude Publica. 2011:27:2041-54.

52. Hanson BS, Liedberg B, Owall B. Social network, social support and dental status in elderly Swedish men. Community Dent Oral Epidemiol. 1994;22:331-7.

53. Wennström A, Ahlqwist M, Stenman U, Björkelund C, Hakeberg M. Trends in tooth loss in relation to socio-economic status among Swedish women aged 38 and 50 years: repeated cross-sectional surveys 1968-2004. BMC Oral Health. 2013;13 https://doi.org/10.1186/1472-6831-13-63.

54. Takeuchi K, Aida J, Kondo K, Osaka K. Social participation and dental health status among older Japanese adults: a population-based cross-sectional study. PLoS One. 2013;8(4):e61741.

55. Rodrigues SM, Oliveira AC, Vargas AM, Moreira AN, E Ferreira EF. Implications of edentulism on quality of life among elderly. Int J Environ Res Public Health. 2012;9(1):100-9. https://doi.org/10.3390/ijerph9010100.

56. Northridge ME, Ue FV, Borrell LN, De La Cruz LD, Chakraborty B, Bodnar S, Marshall S, Lamster IB. Tooth loss and dental caries in community-dwelling older adults in northern Manhattan. Gerodontology. 2012;29:e464-e473. 
57. Leite FRM, Nascimento GG, Scheutz F, López R. Effect of smoking on periodontitis: a systematic review and meta-regression. Am J Prev Med. 2018; https://doi.org/10.1016/j.amepre.2018.02.014.

58. Rauen MS, Moreira EA, Calvo MC, Lobo AS. Oral condition and its relationship to nutritional status in the institutionalized elderly population. J Am Diet Assoc. 2006;106:1112-4.

59. Lee JS, Weyant RJ, Corby P, Kritchevsky SB, Harris TB, Rooks R, Rubin SM, Newman AB. Edentulism and nutritional status in a biracial sample of wellfunctioning, community-dwelling elderly: the health, aging, and body composition study. Am J Clin Nutr. 2004;79:295-302.

60. Susanto H, Nesse W, Kertia N, Soeroso J, Huijser van Reenen Y, Hoedemaker E, Agustina D, Vissink A, Abbas F, Dijkstra PU. Prevalence and severity of periodontitis in Indonesian patients with rheumatoid arthritis. J Periodontol. 2013;84(8):1067-74. https://doi.org/10.1902/jop.2012.110321.

Ready to submit your research? Choose BMC and benefit from:

- fast, convenient online submission

- thorough peer review by experienced researchers in your field

- rapid publication on acceptance

- support for research data, including large and complex data types

- gold Open Access which fosters wider collaboration and increased citations

- maximum visibility for your research: over $100 \mathrm{M}$ website views per year 